\title{
Movement and teaching-motor activities in children with ADHD \\ Rosa Sgambelluri
}

Researcher in Didactics and Special Education

rosa.sgambelluri@unipegaso.it

\section{ABSTRACT}

ADHD is a neurobiological disorder characterized by inattention, impulsivity and motor hyperactivity. Generally, a child with ADHD, it's always not meta-cognitive, inattentive to the procedure implementation to resolve any problem, and it is not sufficiently strategic. Physical activity is for the person with ADHD, the celebration of what it does and what it can be, allowing in this way, a natural inclusion of training skills, knowledge and personal resources.

\section{Keywords:}

movement, body, didactics, ADHD

\section{Council for Innovative Research}

Peer Review Research Publishing System

Journal: International Journal of Research in Education methodology

Vol. 7, No.4

iiremeditor@gmail.com

$\underline{\text { www.ijrem.com }}$ 
If we look at a child's eyes and facial expression and not at his hand moving towards things, it is easy to understand that the gesture is primarily emotional, with active and global involvement of the person, in some cases even the pathos and Eros, and then also communication, relationship, control of physicality.

Instead, on the basis of simplifications very dear to a certain contemporary culture, we get caught up by instrumentalist efficiency and confine the analysis of the gesture in the simple movement of the person towards the object and towards things. On the other hand, we sometimes lose our way in infinite sequences of processes and proprioceptive messages, with their entourage of indications of functional anatomy, much more useful to declaim the complexity of the gesture and its ability to account for the identity of the person.

For some time, however, we have been looking at physical activity from a different perspective, one that is less exposed to generalisations stemming from oversimplifications, and less compromised by the constraints of an approach seduced and compromised by the prospect of complexity. In a view of hermeneutic simplexity and heuristic fertility, it is possible to look furtively at the motor gesture and its complexity through the all-encompassing simplicity of the Self, in which and for which motor activity is natively and perpetually exposed to emotion, communication, relationship and to factors that drive the maturation of imitation and learning.

We can control our movements, reinforce our personal identity and become more confident in interpersonal relationships through our motor characteristics, habitual gestures and posture.

This happens mainly due to problems related to Attention Deficit Hyperactivity Disorder (ADHD), because physical activity that teaches children with this disorder to move is a pleasurable event and allows them to adopt behaviours to support a healthy development.

Attention Deficit Hyperactivity Disorder, or ADHD, is a neurobiological disorder characterised by inattention, impulsivity and hyperactivity ${ }^{1}$.

Early in its history as a distinctly recognisable phenomenon, ADHD was seen as a difficulty or inability of children to learn how to voluntarily manage their behaviour and to follow the rules of social conduct, seen not as a simple matter of etiquette, but as a matter of fundamental moral principles of the time. Today, most scholars believe that a child with ADHD has three main problems: inattention, impulsivity and hyperactivity. Other experts recognise, however, that children with ADHD have other problems, such as difficulty in following rules and instructions and excessive variability in response to situations ${ }^{2}$.

Generally, a child with ADHD is not very metacognitive and not very attentive to the procedure put in place to solve a problem, and is not sufficiently strategic.

Research on cognitive neuropsychology has often found that children with ADHD have attentional problems, especially in tasks that require the application of highly controlled processes and particularly when performing tasks over a long period of time or activities that require a fair amount of cognitive flexibility and use of strategies ${ }^{3}$.

Children with ADHD have poorly controlled behaviour and react to environmental stimuli without adequate reflection. These methods can be explained with a deficit of behavioural inhibition or with a difficulty to sustain a minimum level of waiting with the need for immediate reward. ${ }^{4}$

The behaviour of children with ADHD appears more or less problematic in situations of free play, where there is ample opportunity for movement. They do not have great difficulty in these situations, while in contexts that require rules to be followed, the child is easily labelled as a subject that is difficult to manage.

Play for children with ADHD is stereotyped, with little meaning and characterised by a sequence of simple physical movements.

Subjects with ADHD are always moving and the movements of the legs, arms and trunk are often not harmonious and not aimed at achieving a specific purpose.

Movement for children with ADHD can be the tool through which a result can be achieved, to appreciate its value and, therefore, receive a positive emotional response.

\footnotetext{
${ }^{1}$ Luccherino L., Pezzica S., Sport and ADHD: a residential Summer Camp for adolescents with Attention Deficit Hyperactivity Disorder, Rivista di Psichiatria dell'infanzia e dell'adolescenza,Vol.79, 2012, pp.467-478.

${ }^{2}$ Russell A., Barkley, Taking charge of ADHD. The Complete Authoritative Guide for Parents, Edizioni Alfa Onlus, Roma, 2011, pp.64-66.

${ }^{3}$ Luccherino L., Pezzica S., Sport and ADHD: A residential Summer Camp for adolescents with Attention Deficit Hyperactivity Disorder, Rivista di Psichiatria dell'infanzia e dell'adolescenza,Vol.79, 2012, pp.467-478.

${ }^{4}$ Ibidem.
} 


\section{ISSN 2278-7690}

This is why, through games of movement, a child with ADHD automatically becomes more attentive, and the interest and concentration on the problematic situation becomes a natural and circular process where each piece of information collected is used during the play activity.

In attention deficit and hyperactivity, motor hyperactivity (corporal) is what impairs the normal development and social inclusion of the subject. The repetition of emotions leads to the replication of behaviours, so that habitual attitudes are slowly generated in the subject that are not only noticed in a particular gesture, but are also present in every action.

The usual way of dealing with recurrent experiences generates characteristic and individual attitudes in the child with $\mathrm{ADHD}$, and this personal way of reacting to emotions and expressing them through a specific gesture determines the qualities that are specific to each person. Therefore, actions such as walking, running or writing that appear to be performed the same by everyone are, in fact, performed in a different and individual way by each of us.

During growth, movement allows each subject to experience and learn and to acquire increasingly more difficult abilities, and the repetition of certain experiences, with their perceptions over time, leads to a personal behaviour that becomes permanent.

To understand movement, we must not stop at the exterior and therefore the body, but we must consider the totality of the person in the two components of mind and body, spirit and action. In fact, these two realities interact with each other in such a way that one conditions the other.

Therefore, we must no longer think that a person acts through a body controlled by the mind, but that every movement, every action, every gesture is the result of an ongoing circular relationship between the world of the body and mind.

In this way, physical activities become a real natural vehicle for expressing emotions in a protected container where, via a relational comparison with their peers and the activities proposed, children with ADHD can find a way to invent or re-invent themselves until they arrive at a more balanced and integrated experience of themselves.

For subjects with ADHD, physical activity is the exaltation of what they can do and what they can be, thus allowing a natural educational inclusion between ability, knowledge and personal resources.

Motor activity is also positive in the process of personal maturation and development. In fact, engaging in physical activity means acquiring general and specific motor skills and expanding and diversifying the development of personal skills.

It is also undoubtedly likely that the greatest advantage of physical activity for subjects in difficulty is precisely that of favouring social integration.

Motor activity stimulates growth through group interactions, which in turn increases the educational value and learning occasions within it. Belonging to a group or team, dealing with others, and sharing certain emotions are all fundamental experiences for the growth of a person as a relational being.

This socialising function makes motor activity more important in subjects with ADHD, where experiencing the life of a group is a significant opportunity of development and at the same time allows learning behavioural patterns appropriate for social living.

In this way, the structuring of group play and motor activities capable of helping children with attention deficit hyperactivity disorder becomes particularly effective in the processes of control and self-control through the body-kinaesthetic channel.

The play-educational paths are based generally on the essential purpose of leading the subject to become aware of his body and motor schema thanks to the pedagogical support of experienced teachers ${ }^{6}$.

Educational activities based on motor skills are programmed by stimulating motor problem-solving skills - which are usually lacking in children with ADHD - through stress that can have an open character and can call for an open response, leaving room for creativity and identifying the construction of a personalised motor program, or that can have an open character and call for a closed response, through processes of motor selection, hierarchisation of responses, contextualisation and utilization of motor techniques ${ }^{7}$.

The treatment of attention deficit hyperactivity disorder with physical activity requires specific teaching skills, which are essential for preparing educational programs and methodologies adapted to the special needs of the subject, in the event of individual and group activities of movement. ${ }^{8}$

5 Savarese, G., Iperattività e gestione delle emozioni. Percorsi educativo-didattici e motorio-sportivi,Franco Angeli, Milano, 2009, p.135.

${ }^{6}$ Cazzago, P., Chi riesce a ...? Giochi e problemi motorio-spaziali per i bambini della scuola elementare, Editrice La Scuola, Brescia, 1996.

${ }^{7}$ Savarese, G., Iperattività e gestione delle emozioni. Percorsi educativo-didattici e motorio-sportivi,Franco Angeli, Milano, 2009.

${ }^{8}$ Ibidem. 
The educational implications of ADHD requires teachers to have specific knowledge on psychomotor development, the functioning of systems and equipment, biomechanics and its relationship with movement, psychological characteristics of the subject, usability of the different forms of motor activities (educational, preventive and adaptive re-educational), preparation and set-up of protected spaces in terms of health and hygiene, techniques and motor-sports methodologies, organisation and management of groups, direct and indirect techniques of assistance and on the preparation of new teaching methods such as the laboratory.

The laboratory represents a privileged moment for the recovery of non-verbal languages and assumes a didacticeducational importance aimed at including everyone in the class ${ }^{9}$.

For subjects with ADHD the laboratory must be set up to provide a segmentation of specific activities with ongoing testing, and the interventions must be selected and targeted.

The laboratory focusing on the body and movement is an extraordinary teaching innovation for subjects with ADHD, as it not only stimulates and activates needs and motivations, but also instigates new needs and new motivations.

In fact, it allows transferring knowledge by using the body as a learning channel through which children with ADHD can acquire the knowledge and skills that otherwise would be inaccessible, and also acts as a communication channel to carry emotions and feelings.

A laboratory activity based on physical activity can help subjects with ADHD to recognise their limitations and use them as a basis to learn how to use their body. In addition, the opportunity to operate in a concrete manner and to work together with others are useful conditions to stimulate the subject and make him feel important, offering him the opportunity to increase his capacities in a particularly favourable socio-affective and relational environment.

Music therapy is also a stimulating motor-related laboratory activity for subjects with ADHD. On the one hand, music therapy allows developing attention and turn-taking skills, managing waiting, and impulsivity, and on the other hand, it allows releasing built-up stress and tension. This is achieved through the use of special tools and a combination of physical-musical activities that allow movement and that educate in the context of action, with the alternation of sound and silence, relaxation and excitement, stillness and movement.

\section{References}

1. Berthoz A., La semplessità, Codice edizioni, Torino, 2011.

2. Cazzago P., Chi riesce a ...? Giochi e problemi motorio-spaziali per i bambini della scuola elementare, Editrice La Scuola, Brescia, 1996.

3. Cornoldi C., Difficoltà e disturbi dell'apprendimento, II Mulino, Bologna, 2007.

4. Crispiani P., Capporucci M.L., Giaconi C., Lavorare con il disturbo di attenzione e iperattività. Dalla diagnosi al trattamento educativo, Edizioni Junior, Ranica, 2005.

5. Gomez Paloma, F., Embodied Cognitive Science: Atti incarnati della didattica,Edizioni Nuova Cultura, Roma, 2013.

6. Luccherino L., Pezzica S., Sport and ADHD: a residential Summer Camp for adolescents with Attention Deficit Hyperactivity Disorder, Rivista di Psichiatria dell'infanzia e dell'adolescenza,Vol.79, 2012.

7. Morin E., Le vie della complessità in G. Bocchi e M. Ceruti, La sfida della complessità, Feltrinelli, Milano, 1990.

8. Russell A., Barkley, Prendersi cura dell'ADHD. Una guida autorevole e completa per i genitori, Edizioni Alfa Onlus, Roma, 2011.

9. Savarese, G., Iperattività e gestione delle emozioni. Percorsi educativo-didattici e motorio-sportivi,Franco Angeli, Milano, 2009.

\section{Author's biography}

Dr. Rosa Sgambelluri is a Researcher in Didactics and Special Education at the Pegaso University. She is a PhD in Methodology of Educational Research at the University of Salerno. She has written a book on Sport and motor- didactics in the European schools and published a lot of articles on disability, motor activities and inclusion in the Italian school.

\footnotetext{
${ }^{9}$ Gomez Paloma, F., Embodied Cognitive Science: Atti incarnati della didattica,Edizioni Nuova Cultura, Roma, 2013, p.62.
} 